\title{
PARCERIA UNIVERSIDADE-ESCOLA: CONTRIBUIÇÕES DE QUESTÕES SÓCIOCIENTÍFICAS NO ENSINO DE CIÊNCIAS
}

\author{
Luís Alberto dos Santos Junior ${ }^{1}$ \\ Giselle Faur de Castro Catarino ${ }^{2}$
}

Resumo: O artigo tratou do tema contribuições de questões sócio científicas no ensino de ciências, utilizando CTS como uma base para tais questões. Foram realizadas análises a partir da aplicação de uma sequência didática, baseada em questões sócio científicas que foi levada por um licenciando a aulas de ciências do ensino médio, do município de Duque de Caxias-RJ. Inicialmente estudou-se estratégias para introdução de abordagens de temas científicos baseadas em questões sócio científicas e em controvérsias sócio científicas e socioambientais. O licenciando, junto com os professores da escola e orientador, delimitou diversas situações-problema para questões sócio científicas apontadas pela literatura em ensino de ciências, como situações envolvendo as catástrofes de Chernobyl e Goiás, isto é, utilizamos uma vertente que envolve os temas de energia, um conceito de física muito discutido atualmente por diversas razões. As atividades organizadas foram aplicadas em sala de aula, buscando o diálogo com os alunos e a promoção da parceria entre os professores em formação, exercício e formador. Nossas análises nos levam a inferir que é possível contribuir para uma aprendizagem mais ativa, baseada no diálogo e na investigação sobre controvérsias de situações cotidianas, além de estimular ações colaborativas dos professores e alunos. Entendemos ainda que o desenvolvimento das atividades e análise dos resultados foi fundamental para o processo de formação inicial do licenciando e continuada do professor em exercício e professor orientador a partir das interações entre a escola e a universidade.

Palavras-chave: Questões Sociocientíficas; Ensino de Ciências; Parceria.

\footnotetext{
1 Licenciatura em Matemática/UNIGRANRIO/Escola de Educação-ECELAH, Brasil. E-mail: luis.alberto.eng@poli.ufrj.br.

2 UNIGRANRIO/Programa de Pós Graduação em Ensino de Ciências/Escola de Educação-ECELAH UERJ/Instituto de Física/DFAT, E-mail: gisellefaur@gmail.com.
} 